\title{
Removal And Regeneration of As(V) In Aqueous Solutions By Adsorption On Calcined Fluorapatite: Kinetics And Thermodynamic Parameters.
}

\section{Rachid EL Kaim Billah}

Chouaib Doukkali University: Universite Chouaib Doukkali

\section{Savaş Kaya}

Cumhuriyet university

Selçuk Şimşek ( $\nabla$ simsek@cumhuriyet.edu.tr)

Sivas Cumhuriyet University https://orcid.org/0000-0001-5755-0335

\section{El Mahdi Halim}

Toulouse 3 University: Universite Toulouse III Paul Sabatier

Mahfoud Agunaou

Chouaib Doukkali University: Universite Chouaib Doukkali

Abdessadik Soufiane

Chouaib Doukkali University: Universite Chouaib Doukkali

\section{Research Article}

Keywords: Calcined Fluorapatite, Regeneration, As(V) removal

Posted Date: August 4th, 2021

DOI: https://doi.org/10.21203/rs.3.rs-631962/v1

License: (1) This work is licensed under a Creative Commons Attribution 4.0 International License. Read Full License 


\section{Abstract}

In this work, Fluorapatite has been prepared and successfully applied for the removal of As (VI). The materials prepared have been characterized using X-ray diffraction (XRD), infrared transform transform spectroscopy. Fourier (FTIR), scanning electron microscopy (SEM) and energy dispersive X-ray spectroscopy (EDS). Thermogravimetric analysis (TGA) and zero load point $\mathrm{pH}\left(\mathrm{pH}_{\mathrm{PZC}}\right)$ were also considered as part of these characterizations. In this work, several parameters affecting the adsorption process were studied, such as: the mass effect, time, $\mathrm{pH}$, and the initial concentration effect. The value of the regression coefficient showed that the data The experimental results corresponded best to the pseudo-second order (PSO) model, while the Langmuir adsorption isotherms best described the equilibrium adsorption data with the highest qm of $43.10 \mathrm{mg} / \mathrm{g}$. Finally, FapC has been successfully reused for more than 5 cycles without significant loss of its sorption capacity.

\section{Introduction}

Arsenic is one of the most toxic compounds you can find. Despite their toxicity, inorganic arsenic compounds are naturally present in small amounts on earth. Humans can be exposed to arsenic through food, water and air. Exposure can also occur through skin contact with contaminated soil or water.

Arsenic, classified as a group 1 human carcinogen by the World Health Organization (WHO) (2011), has been reported at significant concentrations in groundwater due to its toxicity and its presence, I World Health Organization (WHO) and the Vietnamese Ministry of Health has set the maximum contaminant for arsenic at $10 \mu \mathrm{g} / \mathrm{L}$ for drinking water (Choong et al. 2007; Sharma and Sohn 2009).

Arsenic can be removed from the water in different ways. Examples of water purification techniques that can be applied are oxidation (van Genuchten et al. 2012), coagulation (Pramanik et al. 2016), chemical precipitation (Harper and Kingham 1992), membrane filtration (Fogarassy et al. 2009), ion exchange (Ning 2002) etc. among these adsorption there are several advantages compared to other methods, due to the low investment cost, ease of use and efficiency of removal of pollutants .

Many absorbents have been reported for the elimination of arsenic $(\mathrm{V})$, such as chitosan (Chen and Chung 2006) Nano-crystalline kaolinie (Amer and Awwad 2018), Treated zeolite (Ahmad and Awwad 2010), activated carbon (Huang and Fu 1984), Natural siderite and hematite (Guo et al. 2007), alumina (Lin and Wu 2001), $\mathrm{Fe}_{7} \mathrm{~S}_{8}$ nanoparticles (Cantu et al. 2016), and Magnetite (Yean et al. 2005). The use of products of natural origin, such as apatite, because they are more abundant and effective as adsorbents

Natural Moroccan phosphates are essentially sedimentary in nature. Phosphate rocks are mainly made up of fluoroapatite $\left(\mathrm{Ca}_{5}\left(\mathrm{PO}_{4}\right)_{3} \mathrm{~F}\right)$ which is weakly crystallized and widely used thanks to its adsorption and ion exchange properties (Cao et al. 2009). The presence of minerals such as calcite and dolomite in the sedimentary apatite is very beneficial for the retention of phosphorus thanks to the good dissolution of these carbonate minerals. This results in an increase in the $\mathrm{pH}$ of the reaction medium and in the 
concentration of $\mathrm{Ca}^{2+}$ ions in solution, which promotes the precipitation of calcium phosphate (Mobasherpour et al. 2011). Apatites have been widely used thanks to their great capacity to immobilize different heavy metals such as $\mathrm{Cd}^{2+}, \mathrm{Pb}^{2+}, \mathrm{Zn}^{2+}, \mathrm{Cu}^{2+}, \mathrm{Ni}^{2+}, \mathrm{Cr}^{6+}$ (Aklil et al. 2004; Yaacoubi et al. 2014).

The proposed exchange mechanisms are different depending on the element considered and the natural conditions. There are ionic exchanges (exchanges on the cationic sites of $\mathrm{Ca}^{2+}$ ) associated with a diffusion in the apatitic structure. During this process, the ionic radius and the electronegativity of the metal ion seem to be the main parameters of this mechanism (Cao et al. 2004).

In this work, two objectives were taken into account: The treatment of Moroccan natural phosphate by a heat treatment The second objective is the elimination of $A s(V)$ dissolved in synthetic solutions by adsorption on calcined phosphate. In this study, we studied the structure and morphology of FApC using $X$-ray diffraction (XRD), transmission electron microscopy (TEM) and scanning electron microscopy (SEM). Information on the structure was also obtained by spectroscopy measurements. Fourier transform infrared spectroscopy (FTIR) measurements, The adsorption capacity of As (V) has been demonstrated using the ICP technique.

\section{Materials And Methods}

\subsection{Materials}

The chemicals used in this study were: Nitric acid $\left(\mathrm{HNO}_{3}\right.$.Sigma-Aldrich. $\left.65 \%\right)$, Sodium hydroxide ( $\mathrm{NaOH}$ Sigma-Aldrich 99\%), Acidhydrochloric (HCL Sigma-Aldrich, 37\%), Sulfuric acid $\left(\mathrm{H}_{2} \mathrm{SO}_{4}\right.$ Sigma-Aldrich, $37 \%$ ), and flourapatite is a sample ofkhouribga-maroc phosphate.

\subsection{Adsorbents preparation}

\subsubsection{Preparation of Fluorapatite (FAP) Calcined}

The natural phosphate used in this work comes from an ore located in Khouribga (Morocco). A determined mass of natural phosphate $(25 \mathrm{~g})$ was transferred to a $500 \mathrm{ml}$ conical flask, adding a volume of $250 \mathrm{~mL}$ of distilled water at $75^{\circ} \mathrm{C}$ for 2 hours. The precipitate is filtered under vacuum, washed with distilled water and then dried in an oven at $100^{\circ} \mathrm{C}$. The dried phosphate was subjected to two treatments, first by nitric acid ( $1 \mathrm{M})$ for 2 hours. Filtered, washed and dried, the solid was calcined at $900^{\circ} \mathrm{C}$. and ground to obtain nanopatites having a grain size of less than 80 mesh.

\subsection{Characterizations}

X-Rays Diffraction analysis was carried out using an Bruker D8 diffractometer operating at $45 \mathrm{kV} / 100$ $\mathrm{mA}$, using CuKa radiation with Ni filter. The surface morphology of the samples was obtained from scanning electron microscopy (SEM) Philips XL 30 ESEM (Acc spot Magn 20.00 kv). FT-IR spectrometer was obtained using a Thermo-scientific Spectrometer in the mid-infrared region between 400 and 4000 
$\mathrm{cm}^{-1}$ with a resolution of $4 \mathrm{~cm}^{-1}$. Thermogravimetric analysis was performed using a Discovery TGA from TA instruments at a heating rate of $10^{\circ} \mathrm{C} / \mathrm{min}$ under nitrogenatmosphere.

\subsection{Adsorption studies}

The adsorption experiments of $\mathrm{As}(\mathrm{V})$ onto composite were carried out in a batch system. The adsorption tests were conducted in glass beakers $(150 \mathrm{~mL})$ containing $50 \mathrm{~mL}$ of $A s(V)$ solutions at a consistent stirring rate. The effects of experimental parameters such as $\mathrm{pH}$, adsorbent mass, contact time, initial chromium concentration on the adsorption process were examined. The initial $\mathrm{pH}$ of the solution was adjusted by the addition of $0.1 \mathrm{M} \mathrm{HCl}$ or $0.1 \mathrm{M} \mathrm{NaOH}$. The concentration of $\mathrm{As}(\mathrm{V})$ in the solution was determined ICP. The adsorption capacity $\mathrm{q}_{\mathrm{t}}(\mathrm{mg} / \mathrm{g})$ and adsorption percentage (\%Removal), at a specified contact time, were calculated using the following equations:

$\mathbf{q}_{\mathbf{t}}=\frac{\left(\mathbf{c}_{\mathrm{o}}-\mathbf{C}_{\mathrm{t}}\right) \mathbf{V}}{\mathbf{m}}$

$\%$ Removal $=\frac{\left(\mathrm{C}_{\mathrm{o}}-\mathrm{C}_{\mathrm{t}}\right)}{\mathrm{C}_{\mathrm{o}}} \times 100$

Where $\mathrm{C}_{\mathrm{o}}$ and $\mathrm{C}_{\mathrm{t}}$ are the amounts of initial and retained $\mathrm{Cr}(\mathrm{VI})$ in the solution at time $\mathrm{t}(\mathrm{mg} / \mathrm{L})$, respectively. $V$ is the solution volume $(L)$ and $m$ is the mass of adsorbent $(g)$.

\subsection{Data Analysis}

In order to describe the mechanism involved in the adsorption process, the experimental kinetic data were analyzed by application of the pseudo-first-order (PFO), the pseudo-second-order (PSO),, while Langmuir and Freundlich models were applied to describe the obtained isotherms to propose the sorption mechanism involved (Table 1). Thermodynamic parameters including the Gibbs free energy $(\Delta G)$, enthalpy $(\Delta \mathrm{H})$, and entropy $(\Delta \mathrm{S})$ were also analyzed to predict the feasibility and determine the nature of the adsorption process in the temperature range of $20-60^{\circ} \mathrm{C}$. 
Table 1. Kinetic and isotherm models
Model
Equation
Description

Kinetic models (Liu et al. 2015; Zhang et al. 2016)

PFO

$$
Q_{t}=Q_{e}\left(1-e^{-k_{1} t}\right)
$$

PSO

$$
\frac{t}{\left[\frac{1}{k_{2} Q_{e}^{2}}\right]+\left[\frac{1}{Q_{e}}\right] t}
$$

$k_{1}\left(\min ^{-1}\right)$ : the PFO rate constant; $t(\min )$ : the contact time of adsorbent and adsorbate; Qt (mg $\mathrm{g}-1$ ): the amount of paraquat adsorbed at time $\mathrm{t}$; Qe (mg g-1): the calculated amount of paraquat adsorbed at equilibrium

$\mathrm{K}_{2}$ : rate constant $\left(\mathrm{g} \mathrm{mg}^{-1} \min ^{-1}\right)$

\begin{tabular}{|c|c|c|}
\hline Langmuir & $Q e=\frac{K_{L} q_{m} C_{e}}{1+K_{L} C_{e}}$ & $\begin{array}{l}q_{e}\left(\mathrm{mg} \mathrm{g}^{-1}\right) \text { : the adsorbed amount of } \mathrm{Cr}(\mathrm{VI}) \text { at } \\
\text { equilibrium } \\
\mathrm{Ce}_{\mathrm{e}}\left(\mathrm{mg} \mathrm{L} \mathrm{L}^{-1}\right) \text { : Concentration of } \mathrm{Cr}(\mathrm{VI}) \text { at } \\
\text { equilibrium. } \\
K_{L}\left(\mathrm{~L} \mathrm{mg}^{-1}\right) \text { : Langmuir constant; } \mathrm{q}_{\mathrm{m}} \text { : maximum } \\
\text { adsorption capacity. }\end{array}$ \\
\hline Freundlich & $Q=K_{f} C_{e}^{n}$ & $\begin{array}{l}K_{F}\left(\mathrm{mg} \mathrm{g}^{-1}\right) \text { : Equilibrium Freundlich constant. } \\
n: \text { Adsorption intensity. }\end{array}$ \\
\hline
\end{tabular}

Isotherm models (Freundlich 1907; Langmuir 1916)

\begin{tabular}{|c|c|c|}
\hline Gibbs free energy & $\Delta \mathrm{G}=-R T \ln k_{d}$ & $\begin{array}{l}\Delta \mathrm{G}\left(\mathrm{kJ} \mathrm{mol}^{-1}\right) \text { : Gibbs free energy change; } \mathrm{Kd} \text { : } \\
\text { equilibrium constant; } \mathrm{R} \text { : gas constant; } \mathrm{T}\left({ }^{\circ} \mathrm{K}\right) \text { : } \\
\text { temperature. }\end{array}$ \\
\hline Van't Hoff & $\ln K_{d}=\frac{\Delta \mathrm{S}^{\circ}}{R}-\frac{\Delta \mathrm{H}^{\circ}}{R T}$ & $\begin{array}{l}\Delta \mathrm{S}^{\circ}\left(\mathrm{kJ} \mathrm{mol}^{-1}\right) \text { : Entropy change; } \Delta \mathrm{H}^{\circ}\left(\mathrm{kJ} \mathrm{mol}^{-}\right. \\
\left.{ }^{1}\right): \text { Enthalpy change } \\
\mathrm{R}: \text { Gas constant }\left(8.314 \mathrm{~J} \cdot \mathrm{mol}^{-1} \cdot \mathrm{K}^{-1}\right)\end{array}$ \\
\hline
\end{tabular}

Thermodynamic data (Tsai and Chang 1995; Hameed et al. 2007)

\subsection{Regeneration study}

Regeneration tests were studied using $100 \mathrm{mg} \mathrm{FapC}$ and $\mathrm{As}(\mathrm{V})$ and $50 \mathrm{ml}$ of $\mathrm{NaOH}$ solution $(0.5 \mathrm{~N})$ under stirring for 2 hours; afterward, the recycled FapC was filtered and washed. The sorption regeneration was repeated five times. 


\section{Results And Discussion}

\subsection{Characterization of FapA}

Figure 1a, shows a good resolution of the XRD peaks, which proves a good crystallinity of the sample, They consist of an apatitic structure, as main constituent, accompanied by quartz SiO2 and fluorite $\mathrm{CaF} 2$, $\mathrm{CaO}$. As can be seen in Fig. 1b, all the FapC diffraction peaks are in agreement with the standard fluorapatite model (JCPDS file no. 15-0876) with a hexagonal structure (Sebti et al. 2003; Billah et al. 2020).

The characterization of fluorapatite by infrared spectroscopy is illustrated in Fig. 2b, all the bands that we have found in this fluorapatite spectrum are in good agreement with the studies reported in other natural or synthetic apatitic phosphates (Mouflih et al. 2005; Elouear et al. 2008).

The IR spectrum of Fapc is characterized by peaks for $\mathrm{OH}$ - at $3570.57 \mathrm{~cm}-1$ and $630.02 \mathrm{~cm}-1$, a group of photos for P043- at $566.97 \mathrm{~cm}-1,602.64 \mathrm{~cm}-1.961,34 \mathrm{~cm}-1.1042,80 \mathrm{~cm}-1$ and at $1091.61 \mathrm{~cm}-1$ and a group of photos for CO32- at $1413.57 \mathrm{~cm}-1$ and at $1455.03 \mathrm{~cm}-1$. The ion absorption bands P043- are characterized by two absorption areas located between $1100-900 \mathrm{~cm}-1$ and $600-500 \mathrm{~cm}-1$ depending on the type of apatite (Raynaud et al. 2002). The bands of the first domain correspond to the symmetrical and antisymmetric vibrations of the P-O bond (Mouflih et al. 2005) and those of the second domain are attributable to the deformation vibrations of the 0-P-O bond (Elouear et al. 2008).

The surface morphology of the FapC has been investigated using SEM.The SEM image of obtained Fap was presented in Fig. 1d. shows that the morphology of the phosphate rock consists mainly of irregularly shaped particles. Other particles are linked to the presence of organic residues and grains of quartz (Aouad et al. 2004a). Coupled with energy dispersive X-ray analysis (EDX) is chow the presence of Ca, P, $\mathrm{O}, \mathrm{C}, \mathrm{F}$ and traces of other elements. This observation confirmed the results found by XRD, IR.

The thermal behavior of Crude and Processed Phosphate was studied by thermogravimetric analysis ATG and its derivative DTG (Fig. 1C). Analysis of the thermogram shows three main mass losses.

The TGA curve of the phosphate studied indicates a first weight loss of $0.52 \%$ between $25^{\circ} \mathrm{C}$ and $250^{\circ} \mathrm{C}$ corresponding to the desorption of water (Aouad et al. 2004b). The second mass loss (4.27\%) Processed Phosphate begins around $200^{\circ} \mathrm{C}$ and which spreads up to $550^{\circ} \mathrm{C}$ corresponds to the elimination of organic matter (El Asri et al. 2009). The last weight loss of $5.38 \%$ between $450^{\circ} \mathrm{C}$ and $1100^{\circ} \mathrm{C}$ is attributed to the decomposition of mineral carbonates (El Asri et al. 2009).

The DTA curve showed the presence of an endothermic effect at $60^{\circ} \mathrm{C}$ attributed to the evaporation of water adsorbed on the surface of the phosphate and exothermic peak at $360^{\circ} \mathrm{C}$ and picendothermiqu $697^{\circ} \mathrm{C}$ attributed respectively to combustion of organic matter and decomposition of carbonates (Aouad et al. 2004a).

\subsection{Adsorption studies}




\subsubsection{The effect of $\mathrm{pH}$}

The influence of $\mathrm{pH}$ on the adsorption of $\mathrm{As}(\mathrm{V})$ on FapC was studied in a $\mathrm{pH}$ range of 1.0 to 12 , using 0.1 $\mathrm{g}$ of FapC in a solution of $50 \mathrm{ml}$ of $A s(V)\left(10 \mathrm{mg} \mathrm{L}^{-1}\right)$ for 1 hour at room temperature. The $\mathrm{pH}$ was adjusted using $0.1 \mathrm{M} \mathrm{NaOH}$ and $0.1 \mathrm{M} \mathrm{HCl}$. The results are shown in Fig. 2a. shows that the percentage of As (V) elimination increases sharply with the increase in the $\mathrm{pH}$ of As $(\mathrm{V})$ from 1.0 to 8.0 and then remains stable between 8 and 12. The Pourbaix diagram for As species (Garcia et al. 2014) indicates that the stable oxidation state, $\mathrm{As}(\mathrm{V})$ in the aqueous system is a monovalent anion $\left(\mathrm{H}_{2} \mathrm{AsO}_{4}{ }^{-}\right)$in the $\mathrm{pH}$ range of 3.0-6.8 or equivalent $\left(\mathrm{HAsO}_{4}{ }^{2-}\right)$ anion in the $\mathrm{pH}$ range of 7.0-11.0. The removal efficiency of As $(\mathrm{V})$ increases on the negatively charged surface $\left(>\mathrm{pH}_{\mathrm{PZC}}\right)$ of the adsorbents. The results therefore indicate the exchange of arsenate for phosphate in the FApc structure (Çiftçi et al. 2011).

\subsubsection{The effect of adsorbent mass}

The effect of the dose of FapC on removal of As $(V)$ displayed in Fig. 2b The influence of the mass of the adsorbent has been studied in the range $0.025-0.400 \mathrm{~g}$ shows that the percentage of elimination of As (V) increases with the increase in the quantity of adsorbent then it remains stable. As in Fig. 3 shows that $100 \mathrm{mg}$ of FapC is capable of fixing a maximum of $A s(V)$ on the order of $90 \%$ of $A s(V)\left(C_{i}: 100 \mathrm{mgL}^{-1}\right)$. The amounts of As $(V)$ fixed must be in accordance with the doses of adsorbent in solution to ensure an equivalent number of adsorption sites (Sebti et al. 2003).

\subsubsection{The effect of contact time}

Figure 2c illustrates the adsorption of metal ions of $A s(V)$ on FapC with different contact times (0 to 120 $\mathrm{min})$ with the at $\mathrm{pH} 8$ and the mass equal to $100 \mathrm{mg}$. The retention of $\mathrm{As}(\mathrm{V})$ on FapC increases with increasing contact time and reaches a saturation phase at around 60 minutes, from which time the retention becomes almost constant. It's a two-phase process. In the first phase, contact time less than 60 minutes, the adsorption is due to the availability of a large number of active sites as well as to the rapid diffusion of metal ions, from the solution to the surface of the solid. In the second phase, the adsorption reached a saturation equilibrium of the adsorbent sites on the FapC.

\subsubsection{Adsorption kinetics}

To examine the adsorption kinetics of As $(\mathrm{V})$ metal ion onto FapC and the mechanism and ratecontrolling step in the whole adsorption process, the nonlinear forms of pseudo-first-order (PFO), Table 2 summarizes the analogous parameters for the adsorption of As $(\mathrm{V})$ metal ions on FapC. The results showed that the $\mathrm{R}^{2}$ of PSO exhibits a honeyed connection of the metal ion As (V) on FapC as opposed to the PFO parameters. In addition, the PSO model shows well-coordinated correlations between the calculated values of $Q_{\text {cal }}\left(\mathrm{Fa}: 23.49 \mathrm{mg} \mathrm{g}^{-1}\right)$ and the experimental values of Qe (Fa: $22.68 \mathrm{mg} / \mathrm{g}$ ) pseudo-second -order (PSO) are used (Table 2). 
Table 2

Kinetics adsorption parameters of $\mathrm{As}(\mathrm{V})$ on FapC.

\begin{tabular}{|c|c|c|c|c|c|c|c|}
\hline & \multirow[t]{2}{*}{$\begin{array}{l}Q_{e, \exp } \\
\left(\mathrm{mg} \mathrm{g}^{-1}\right)\end{array}$} & \multicolumn{2}{|c|}{ Pseudo-First-Order model } & \multicolumn{4}{|c|}{$\begin{array}{l}\text { Pseudo-Second-Order } \\
\text { model }\end{array}$} \\
\hline & & $\begin{array}{l}Q_{e, c a l} \\
\left(\mathrm{mg} \mathrm{g}^{-1}\right)\end{array}$ & $\begin{array}{l}K_{1} \\
\left(\min ^{-1}\right)\end{array}$ & $\mathrm{R}^{2}$ & $\begin{array}{l}Q_{e, c a l} \\
\left(\mathrm{mg} \mathrm{g}^{-1}\right)\end{array}$ & $\begin{array}{l}\mathrm{K}_{2} \\
\left(\mathrm{~g} \mathrm{mg}^{-1} \cdot \mathrm{min}^{-1}\right)\end{array}$ & $\mathrm{R}^{2}$ \\
\hline CS & 22.68 & 25.73 & 0.1 & 0.981 & 23.49 & 0.003 & 0.999 \\
\hline
\end{tabular}

\subsubsection{Adsorption isotherms}

The Langmuir and Freundlich isotherms (Table 2) have been useful in defining the adsorption capacity of FapC for the metal ion As (V) (van Genuchten et al. 2012). The adjustment diagrams of the Langmuir and Freundlich isotherm models for the adsorption of As $(\mathrm{V})$ on Fapc are presented in Fig. 4. The calculated isotherm parameters, as well as the correlation coefficients $\left(R^{2}\right)$, are defined in Table 3 . Rendered at $R^{2}$ values, the Langmuir model was better suited than the Freundlich model to experimental data for the adsorption of metal ions As (V). Due to the Langmuir model established on the assumption of homogeneous adsorption, it can be said that the adsorption of the metal ion As (V) on the surface FapC is homogeneous.

Table 3

Equilibrium adsorption parameters of $\mathrm{As}(\mathrm{V})$ on FapC.

\begin{tabular}{|c|c|c|c|c|c|c|}
\hline & \multicolumn{3}{|c|}{ Langmuir } & \multicolumn{3}{|c|}{ Freundlich } \\
\hline & $\begin{array}{l}\text { Qmax } \\
(\mathrm{mg} / \mathrm{g})\end{array}$ & $\begin{array}{l}\mathrm{K}_{\mathrm{L}} \\
\left(\mathrm{L} \cdot \mathrm{min}^{-1}\right)\end{array}$ & $\mathrm{R}^{2}$ & $\begin{array}{l}\mathrm{K}_{\mathrm{F}} \\
(\mathrm{mg} / \mathrm{g})\end{array}$ & $\mathrm{n}$ & $\mathrm{R}^{2}$ \\
\hline FapC & 43.10 & 0.25 & 0.979 & 10.65 & 0.39 & 0.968 \\
\hline
\end{tabular}

Thermodynamic parameters are one of the essential tools for predicting the adsorption mechanism, whether it is a physisorption or chemisorption process. Thermodynamic parameters could be determined from the thermodynamic laws as they are. presented in Table 4 (Fig. 5). The positive amounts of $\Delta \mathrm{H}^{\circ}$ $(-32.549$ and $-20.095 \mathrm{~J} / \mathrm{mol})$ confirm that the adsorption of the metal by the marl clay is endothermic. This means that the system absorbs heat from the outside environment. We also found a positive value of $\Delta S$ which suggests that the As $(V)$ are adsorbed in a random way on the surface of the Fap. The negative values of $\Delta G^{\circ}$ indicate that the adsorption of the $A s(V)$ on Fapc is spontaneous (Cao et al. 2004). 
Table 4

Thermodynamics parameters of $\mathrm{Cr}(\mathrm{VI})$ using $\mathrm{CS}$ and $\mathrm{CS}-\mathrm{Fa}$

\begin{tabular}{|c|c|c|c|c|c|}
\hline & \multirow{2}{*}{$\begin{array}{l}\Delta \mathrm{H}^{\circ} \\
(\mathrm{KJ} / \mathrm{mol})\end{array}$} & \multirow{2}{*}{$\begin{array}{l}\Delta \mathrm{S}^{\circ} \\
(\mathrm{J} / \mathrm{mol} . \mathrm{K})\end{array}$} & \multicolumn{3}{|c|}{$\Delta \mathrm{G}^{\circ}(\mathrm{KJ} / \mathrm{mol})$} \\
\hline & & & $298 \mathrm{~K}$ & $318 \mathrm{~K}$ & $333 \mathrm{~K}$ \\
\hline FapC & 5.133 & 15.921 & -2.876 & -4.368 & -9.142 \\
\hline
\end{tabular}

\subsection{Regeneration}

The capacities of fapC composites to regenerate after adsorption of metals using various desorbing agents $(\mathrm{NaOH}, \mathrm{NaCl}$ and $\mathrm{HCl}$ ) with a concentration of $0.5 \mathrm{M}$, is described in Fig. 6 . The best results were obtained using $0.5 \mathrm{M} \mathrm{NaOH}$ for a contact time of $16 \mathrm{~h}$, and allowed $90 \%$ of adsorbed $\mathrm{As}(\mathrm{V})$ to be recovered. After the desorption experiment with $0.5 \mathrm{M} \mathrm{NaOH}$, the adsorbent was filtered from solution, washed with distilled water, dried at $100^{\circ} \mathrm{C}$ and reused for the adsorption of $\mathrm{As}(\mathrm{V})$. The figure shows Fapc desorption. We can see that the absorption capacity of As (V) using FapC composite decreased slightly after two cycles from $90.8-82.5 \%$ in the fifth cycle. The performance decreased by $8.3 \%$, Les results concluded that Fap is reusable and effective for four cycles of desorption.

\subsection{Adsorption mechanism of As(V) on FapC.}

The FTIR spectra of FapC before and after the adsorption of As $(V)$ are presented in Fig. The FTIR spectra were obtained in order to analyze the mechanism of the Adsorption of $A s(V)$ and identification of the functional groups on the surface Fluorapatite. As revealed in Fig. 7 the peaks correpond to PO43- have been moved from 1021.2, 560.7 and $600.3 \mathrm{~cm}-1$ to $1019,8,558.04$ and $599.3 \mathrm{~cm}-1$, respectively. This can be attributed to the complexation between As (V) ions with a P043- group.

\section{Conclusion}

The results obtained in this research work demonstrated the effectiveness of calcined Fluorapatite (FapC) as an effective and environmentally friendly adsorbent for the removal of As (V) from aqueous solutions. The results of XRD, SEM/EDS and FTIR and TGA/TDA have shown that the conditioning methods allowed to generate a material with adsorbent properties ideal for the removal of arsenic from contaminated water. The adsorption kinetic data of As $(\mathrm{V})$ onto FapC fitted well the pseudo-second-order kinetic. The coefficientof regression (R2) that was obtained using the Langmuir model was higher compared to that obtainedusing the Freundlich model. Values of thermodynamic functionsshow that the reaction is endothermic, random and beneficial .Moreover, FapC showed high sorption efficiency of As (V) (90.8\%) after 2 Cycles of adsorption-regeneration. it can be concluded that FapC had an effective adsorbent which can be used in many environmental applications. After emphasizing above mentioned adsorptive features, the adsorption capacity of FacC for arsenic ions were compared with those extracted from literature. As can be seen in Table 5, FapC is potential adsorbent with comparable capacity. 
Table 5

Comparison of As (V) adsorption capacity by different adsorbents.

\begin{tabular}{|lll|}
\hline Adsorbent & $\mathbf{Q}_{\max }$ (mg.g $^{-1}$ ) & Reference \\
\hline Chitosan & 1.94 & (Sethy and Sahoo 2019) \\
\hline Nano-crystalline kaolinie & 43.67 & (Salgado-gómez et al. 2014) \\
\hline Treated Zoelite & 18.35 & (Yu et al. 2017) \\
\hline Microporous Activated Carbone & 132 & (Chen et al. 2013) \\
\hline Natural siderite and hematite & 0.16 & (Li et al. 2013) \\
\hline Alumina & 25 & (Xiao et al. 2013) \\
\hline Fe $S_{8}$ nanoparticles & 31.30 & (Zhang et al. 2016) \\
\hline Magnetite & 46.70 & (Liu et al. 2015) \\
FapC & 43.10 & This study \\
\hline
\end{tabular}

\section{Declarations}

\section{Author contributions:}

Rachid EL Kaim Billah, wrote the paper, conducted review and editing, designed research ; Savaş Kaya, wrote the paper, conducted review and editing, designed research ; Selçuk Şimşek, wrote the paper, conducted review and editing, designed research ; El Mahdi Halim, wrote the paper, designed research ; Mahfoud Agunaou, wrote the paper, designed research ; Abdessadik Soufiane, wrote the paper, designed research

Compliance with Ethics Requirements: Authors have no financial relationship with the organization that sponsored the research.

Conflict of Interest: Authors declares that there are no conflicts of interest.

Ethical Approval: This article does not contain any studies with human or animal subjects.

Informed consent: On behalf of other authors, the informed consent was obtained from all individual participants included in the study.

Funding : Not applicable

Availability of data and materials : Not applicable

Consent to Publish : Not applicable 
Acknowledgment:

The authors would like to acknowledge the support of the University of Chouaiib Doukkali.

\section{References}

1. Ahmad RA, Awwad AM (2010) Thermodynamics of As(V) Adsorption onto Treated Granular Zeolitic Tuff from Aqueous Solutions. J Chem Eng Data 55:3170-3173. https://doi.org/10.1021/je100034p

2. Aklil A, Mouflih M, Sebti S (2004) Removal of heavy metal ions from water by using calcined phosphate as a new adsorbent. J Hazard Mater 112:183-190. https://doi.org/10.1016/j.jhazmat.2004.05.018

3. Amer MW, Awwad AM (2018) Removal of As(V) from aqueous solution by adsorption onto nanocrystalline kaolinite: Equilibrium and thermodynamic aspects of adsorption. Environmental Nanotechnology Monitoring Management 9:37-41. https://doi.org/10.1016/j.enmm.2017.12.001

4. Aouad A, Benchanâa M, Mokhlisse A, Arafan A (2004a) Study of thermal behaviour of organic matter from natural phosphates (Youssoufia - Morocco). J Therm Anal Calorim 70:593-603. https://doi.org/10.1023/a:1021601329760

5. Aouad A, Benchanâa M, Mokhlisse A, Ounas A (2004b) Thermal analysis of Moroccan phosphates "Youssoufia" in an oxidative atmosphere by TG and DSC. J Therm Anal Calorim 75:887-900. https://doi.org/10.1023/b:jtan.0000027183.13313.c0

6. Billah REK, Abdellaoui Y, Anfar Z et al (2020) Synthesis and Characterization of Chitosan/Fluorapatite Composites for the Removal of $\mathrm{Cr}(\mathrm{VI})$ from Aqueous Solutions and Optimized Parameters. Water Air Soil Pollut 231:163. https://doi.org/10.1007/s11270-020-04535-9

7. Cantu J, Gonzalez LE, Goodship J et al (2016) Removal of arsenic from water using synthetic Fe7S8 nanoparticles. Chem Eng J 290:428-437. https://doi.org/10.1016/j.cej.2016.01.053

8. Cao X, Ma LQ, Rhue DR, Appel CS (2004) Mechanisms of lead, copper, and zinc retention by phosphate rock. Environ Pollut 131:435-444. https://doi.org/10.1016/j.envpol.2004.03.003

9. Cao X, Wahbi A, Ma L et al (2009) Immobilization of $\mathrm{Zn}, \mathrm{Cu}$, and $\mathrm{Pb}$ in contaminated soils using phosphate rock and phosphoric acid. J Hazard Mater 164:555-564.

https://doi.org/10.1016/j.jhazmat.2008.08.034

10. CHEN C-C, CHUNG Y-C (2006) Arsenic Removal Using a Biopolymer Chitosan Sorbent. Journal of Environmental Science Health Part A 41:645-658. https://doi.org/10.1080/10934520600575044

11. Chen D, Li W, Wu Y et al (2013) Preparation and characterization of chitosan / montmorillonite magnetic microspheres and its application for the removal of $\mathrm{Cr}(\mathrm{VI}) .221: 8-15$.

https://doi.org/10.1016/j.cej.2013.01.089

12. Choong TSY, Chuah TG, Robiah Y et al (2007) Arsenic toxicity, health hazards and removal techniques from water: an overview. Desalination 217:139-166.

https://doi.org/10.1016/j.desal.2007.01.015

Page $11 / 20$ 
13. Çiftçi TD, Yayayürük O, Henden E (2011) Study of arsenic(III) and arsenic(V) removal from waters using ferric hydroxide supported on silica gel prepared at low pH. Environ Technol 32:341-351. https://doi.org/10.1080/09593330.2010.499546

14. El Asri S, Laghzizil A, Alaoui A et al (2009) Structure and thermal behaviors of Moroccan phosphate rock (Bengurir). J Therm Anal Calorim 95:15-19. https://doi.org/10.1007/s10973-008-9114-z

15. Elouear Z, Bouzid J, Boujelben $\mathrm{N}$ et al (2008) Heavy metal removal from aqueous solutions by activated phosphate rock. J Hazard Mater 156:412-420.

https://doi.org/10.1016/j.jhazmat.2007.12.036

16. Fogarassy E, Galambos I, Bekassy-Molnar E, Vatai G (2009) Treatment of high arsenic content wastewater by membrane filtration. Desalination 240:270-273.

https://doi.org/10.1016/j.desal.2007.11.078

17. Freundlich H (1907) Über die Adsorption in Lösungen. Z f Ã¹/4r Phys Chem 57U:385-470. https://doi.org/10.1515/zpch-1907-5723

18. Garcia S, Sardar S, Maldonado S et al (2014) Study of As(III) and As(V) oxoanion adsorption onto single and mixed ferrite and hausmannite nanomaterials. Microchem J 117:52-60. https://doi.org/10.1016/j.microc.2014.06.008

19. Guo H, Stüben D, Berner Z (2007) Removal of arsenic from aqueous solution by natural siderite and hematite. Appl Geochem 22:1039-1051. https://doi.org/10.1016/j.apgeochem.2007.01.004

20. Hameed BH, Ahmad AA, Aziz N (2007) Isotherms, kinetics and thermodynamics of acid dye adsorption on activated palm ash. Chem Eng J 133:195-203. https://doi.org/10.1016/j.cej.2007.01.032

21. Harper TR, Kingham NW (1992) Removal of arsenic from wastewater using chemical precipitation methods. Water Environ Res 64:200-203. https://doi.org/10.2175/WER.64.3.2

22. Huang CP, Fu PLK (1984) Treatment of Arsenic(V)-Containing Water by the Activated Carbon Process. Journal (Water Pollution Control Federation) 56:233-242

23. Langmuir I (1916) THE CONSTITUTION AND FUNDAMENTAL PROPERTIES OF SOLIDS AND LIQUIDS. PART I. SOLIDS. J Am Chem Soc 38:2221-2295. https://doi.org/10.1021/ja02268a002

24. Li L, Fan L, Sun M et al (2013) Adsorbent for hydroquinone removal based on graphene oxide functionalized with magnetic cyclodextrin-chitosan. Int J Biol Macromol 58:169-175. https://doi.org/10.1016/j.ijbiomac.2013.03.058

25. Lin T-F, Wu J-K (2001) Adsorption of Arsenite and Arsenate within Activated Alumina Grains: Equilibrium and Kinetics. Water Res 35:2049-2057. https://doi.org/10.1016/S0043-1354(00)00467$\mathrm{X}$

26. Liu Q, Yang B, Zhang L, Huang R (2015) Adsorptive removal of $\mathrm{Cr}(\mathrm{VI})$ from aqueous solutions by cross-linked chitosan/bentonite composite. Korean J Chem Eng 32:1314-1322. https://doi.org/10.1007/s11814-014-0339-1

27. Mobasherpour I, Salahi E, Pazouki M (2011) Removal of nickel (II) from aqueous solutions by using nano-crystalline calcium hydroxyapatite. Journal of Saudi Chemical Society 15:105-112. 
https://doi.org/10.1016/j.jscs.2010.06.003

28. Mouflih M, Aklil A, Sebti S (2005) Removal of lead from aqueous solutions by activated phosphate. J Hazard Mater 119:183-188. https://doi.org/10.1016/j.jhazmat.2004.12.005

29. Ning RY (2002) Arsenic removal by reverse osmosis. Desalination 143:237-241. https://doi.org/10.1016/S0011-9164(02)00262-X

30. Pramanik BK, Pramanik SK, Suja F (2016) Removal of arsenic and iron removal from drinking water using coagulation and biological treatment. J Water Health 14:90-96. https://doi.org/10.2166/wh.2015.159

31. Raynaud S, Champion E, Bernache-Assollant D, Thomas P (2002) Calcium phosphate apatites with variable $\mathrm{Ca} / \mathrm{P}$ atomic ratio $\mathrm{I}$. Synthesis, characterisation and thermal stability of powders. Biomaterials 23:1065-1072. https://doi.org/10.1016/S0142-9612(01)00218-6

32. Salgado-gómez N, Macedo-miranda MG, Olguín MT (2014) Applied Clay Science Chromium VI adsorption from sodium chromate and potassium dichromate aqueous systems by hexadecyltrimethylammonium-modi fi ed zeolite-rich tuff. Appl Clay Sci. https://doi.org/10.1016/j.clay.2014.04.013

33. Sebti S, Solhy A, Tahir R et al (2003) Application of natural phosphate modified with sodium nitrate in the synthesis of chalcones: a soft and clean method. J Catal 213:1-6. https://doi.org/10.1016/S0021-9517(02)00017-9

34. Sethy TR, Sahoo PK (2019) Highly toxic Cr (VI) adsorption by (chitosan-g-PMMA)/silica bionanocomposite prepared via emulsifier-free emulsion polymerisation. Int J Biol Macromol 122:1184-1190. https://doi.org/10.1016/j.ijbiomac.2018.09.069

35. Sharma VK, Sohn M (2009) Aquatic arsenic: Toxicity, speciation, transformations, and remediation. Environ Int 35:743-759. https://doi.org/10.1016/j.envint.2009.01.005

36. Tsai W-T, Chang C-Y (1995) Surface characterization and thermodynamics of adsorption of methylene chloride on activated carbons. Journal of Environmental Science Health Part A: Environmental Science Engineering Toxicology 30:525-535. https://doi.org/10.1080/10934529509376215

37. van Genuchten CM, Addy SEA, Peña J, Gadgil AJ (2012) Removing Arsenic from Synthetic Groundwater with Iron Electrocoagulation: An Fe and As K-Edge EXAFS Study. Environ Sci Technol 46:986-994. https://doi.org/10.1021/es201913a

38. Xiao Y, Liang H, Chen W, Wang Z (2013) Applied Surface Science Synthesis and adsorption behavior of chitosan-coated MnFe 204 nanoparticles for trace heavy metal ions removal. Appl Surf Sci 285:498-504. https://doi.org/10.1016/j.apsusc.2013.08.083

39. Yaacoubi H, Zidani O, Mouflih M et al (2014) Removal of Cadmium from Water Using Natural Phosphate as Adsorbent. Procedia Eng 83:386-393. https://doi.org/10.1016/j.proeng.2014.09.039

40. Yean S, Cong L, Yavuz CT et al (2005) Effect of magnetite particle size on adsorption and desorption of arsenite and arsenate. J Mater Res 20:3255-3264. https://doi.org/10.1557/jmr.2005.0403 
41. Yu P, Wang H, Bao R et al (2017) Self-Assembled Sponge-like Chitosan/Reduced Graphene Oxide/ Montmorillonite Composite Hydrogels without Cross-Linking of Chitosan for $\mathrm{E} f f$ ective $\mathrm{Cr}(\mathrm{VI})$ Sorption. https://doi.org/10.1021/acssuschemeng.6b02254

42. Zhang L, Luo H, Liu P et al (2016) A novel modified graphene oxide/chitosan composite used as an adsorbent for $\mathrm{Cr}(\mathrm{VI})$ in aqueous solutions. Int J Biol Macromol 87:586-596. https://doi.org/10.1016/j.ijbiomac.2016.03.027

\section{Figures}



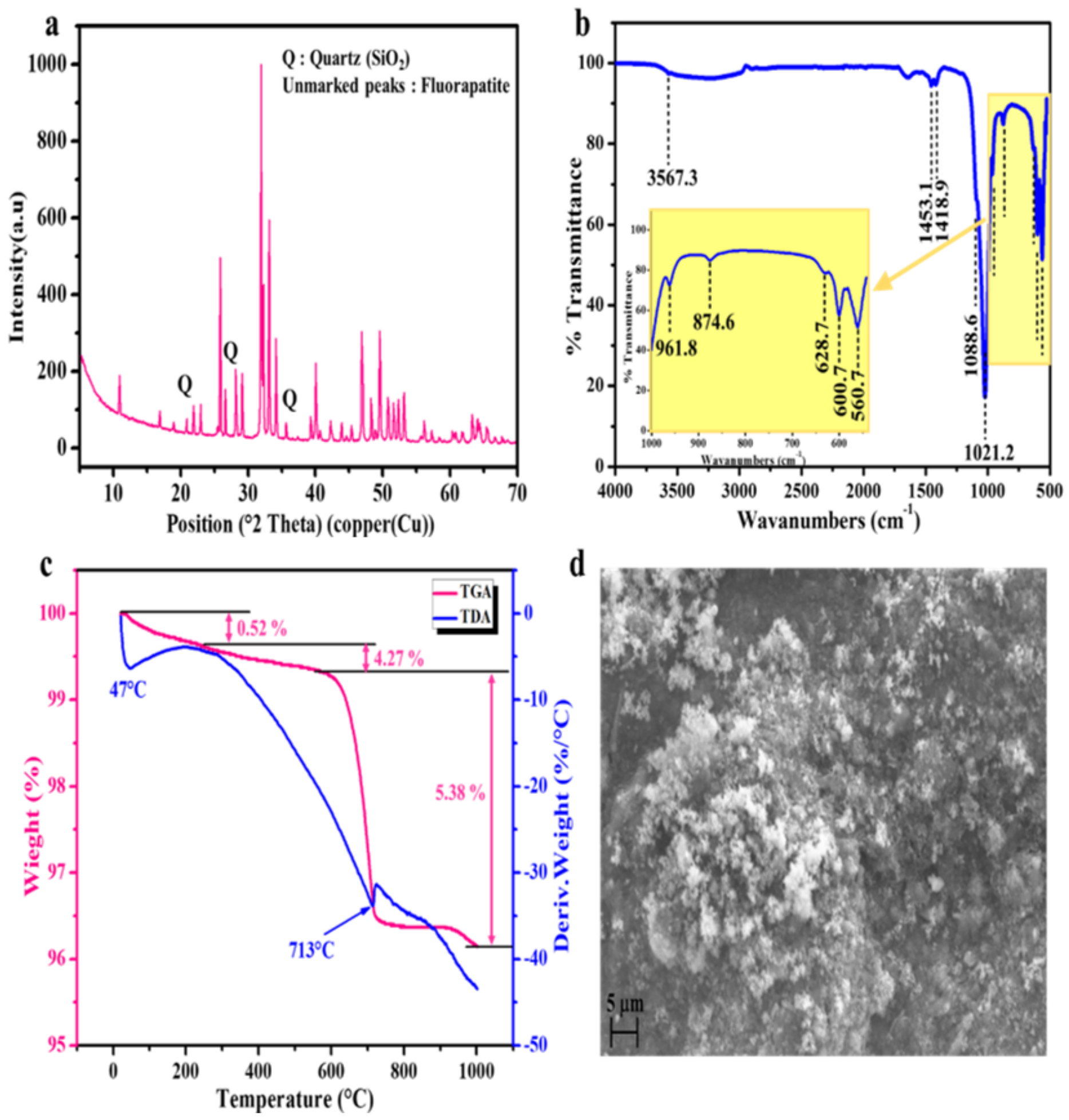

d

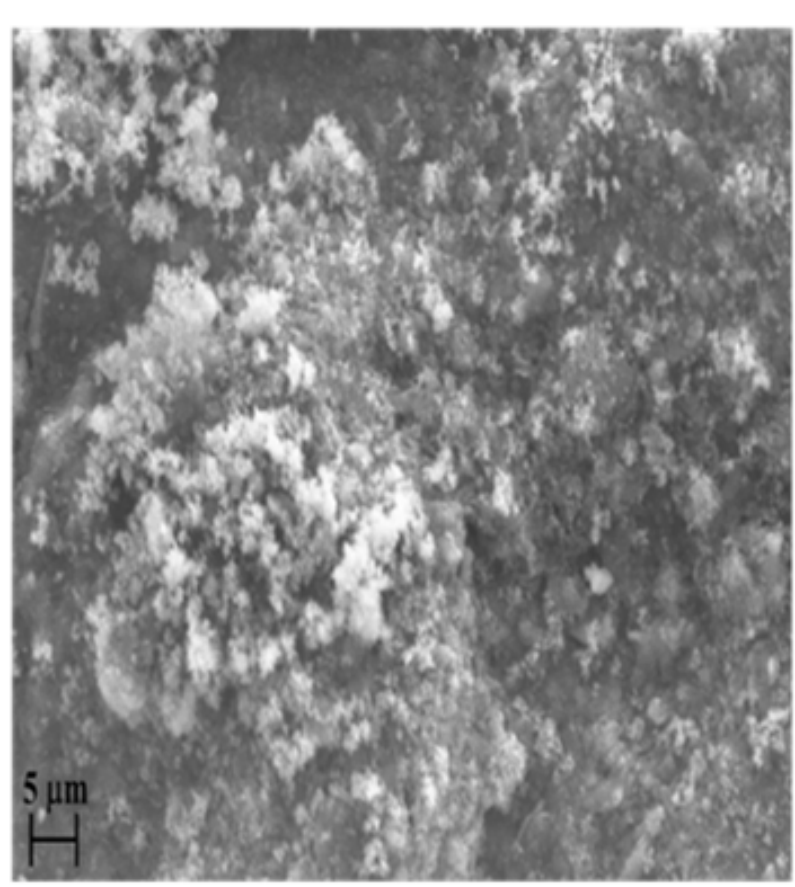

Figure 1

X-Rays patterns (a), FTIR spectra (b), TGA and DTA (c) curves, and SEM image (d) of Fluorapatite (FapC) 

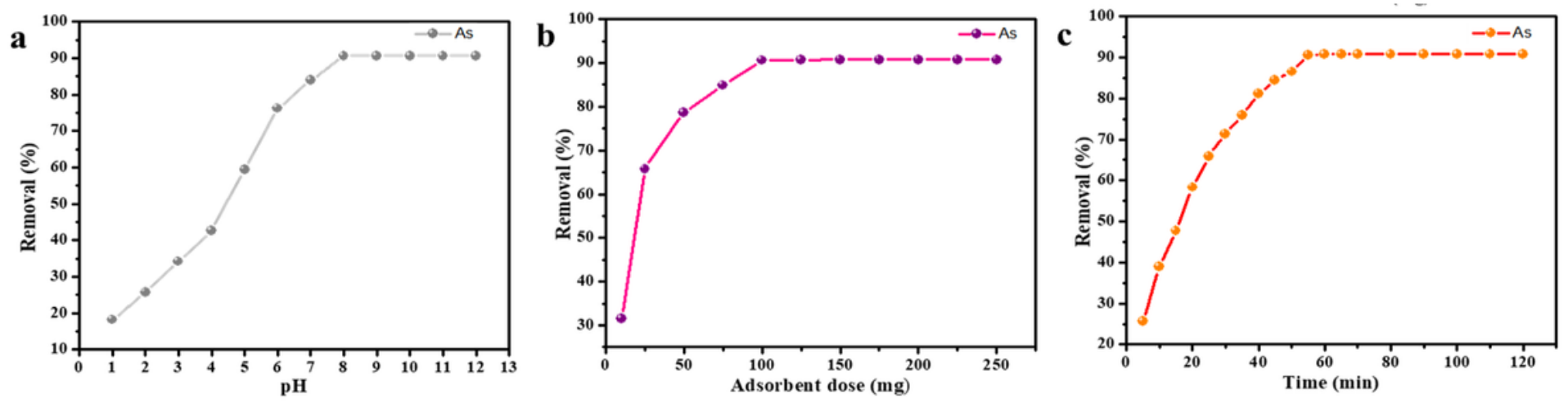

Figure 2

Effect of pH solution (a), adsorbent mass (b), and contact time (c) on adsorption of As (V).

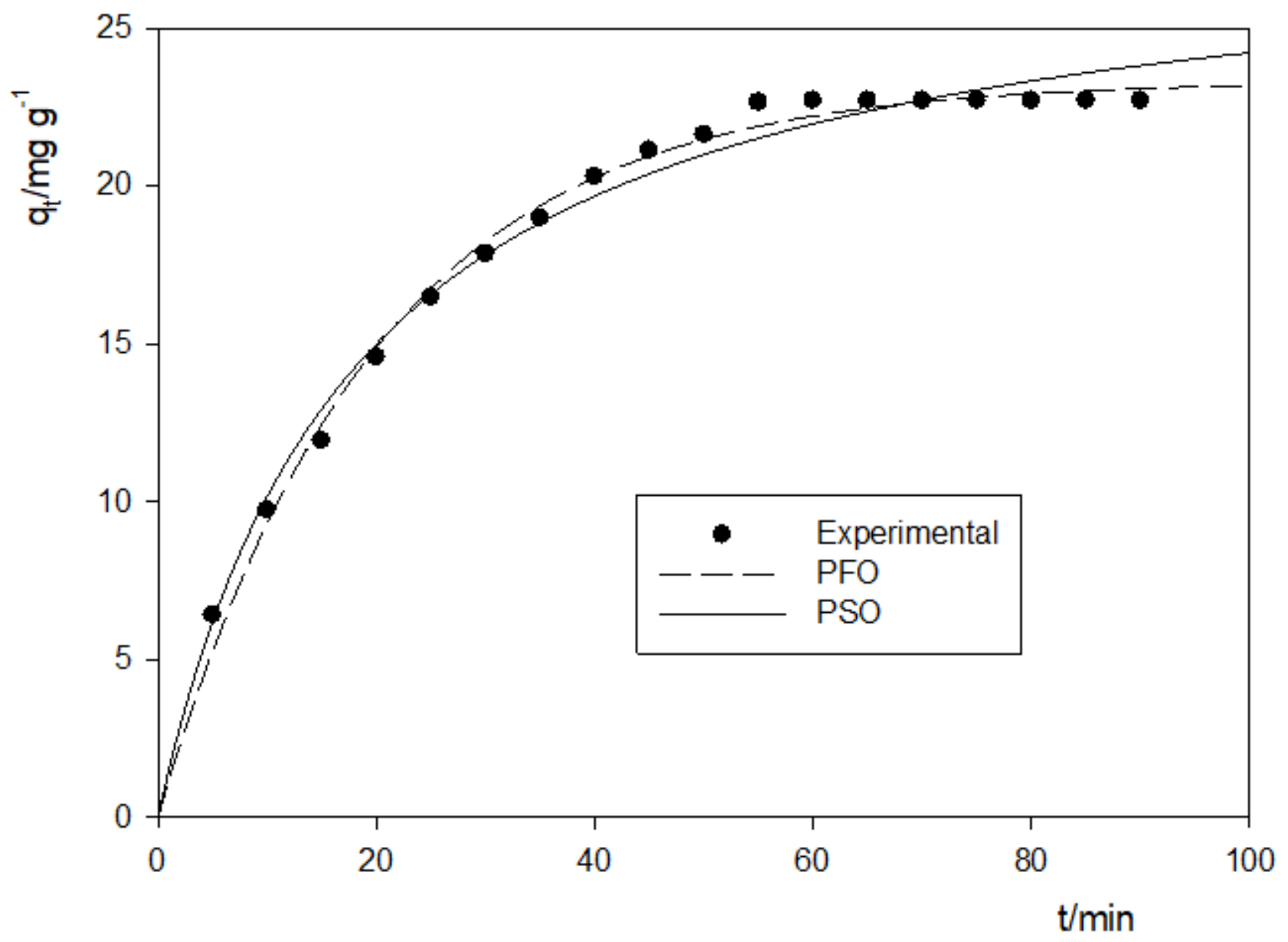

Figure 3

Kinetic studies by PFO, PSO. 


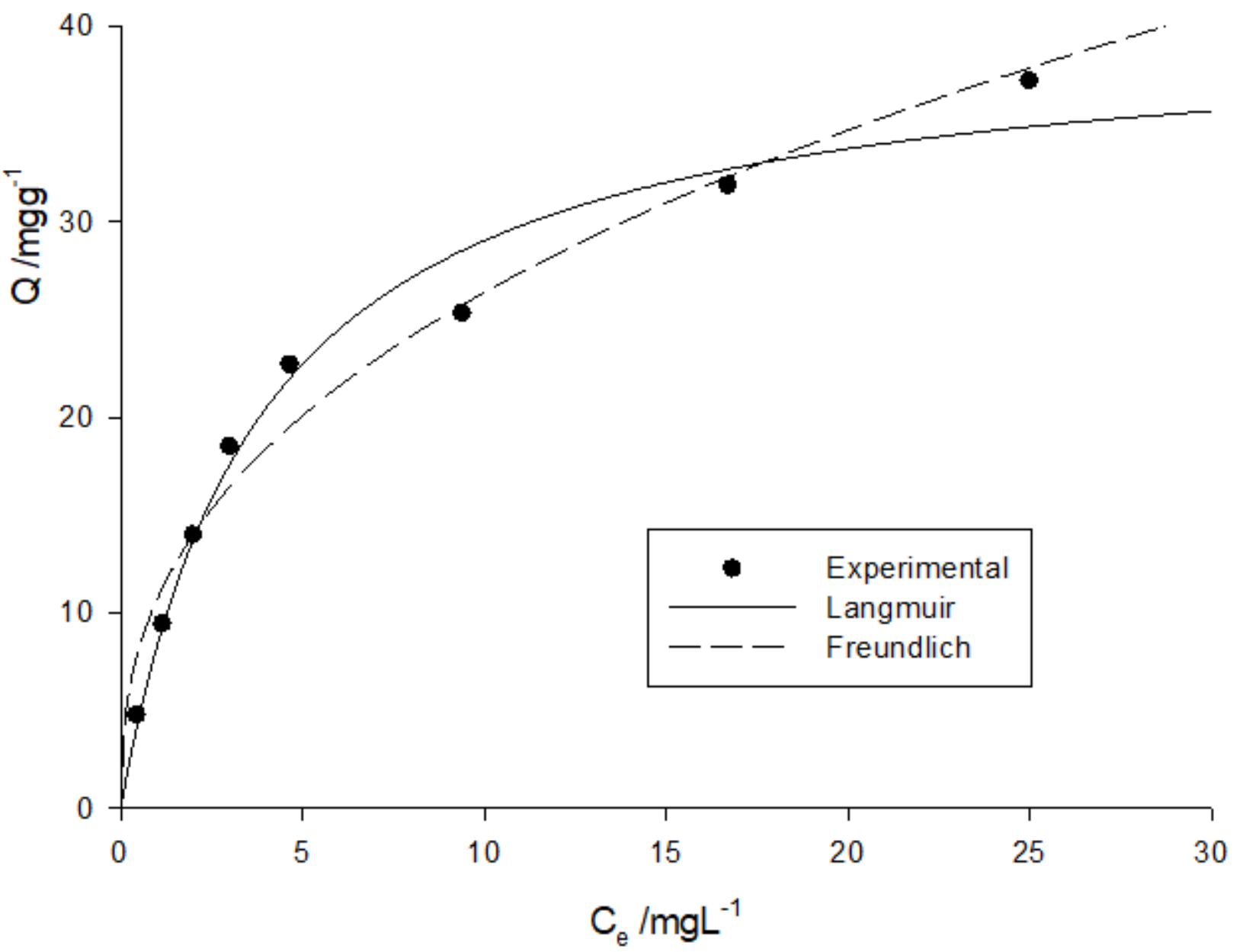

\section{Figure 4}

Nonlinear representations of teh Langmuir and Freundlich models for the adsorption of $A s(V)$ ion onto FapC 


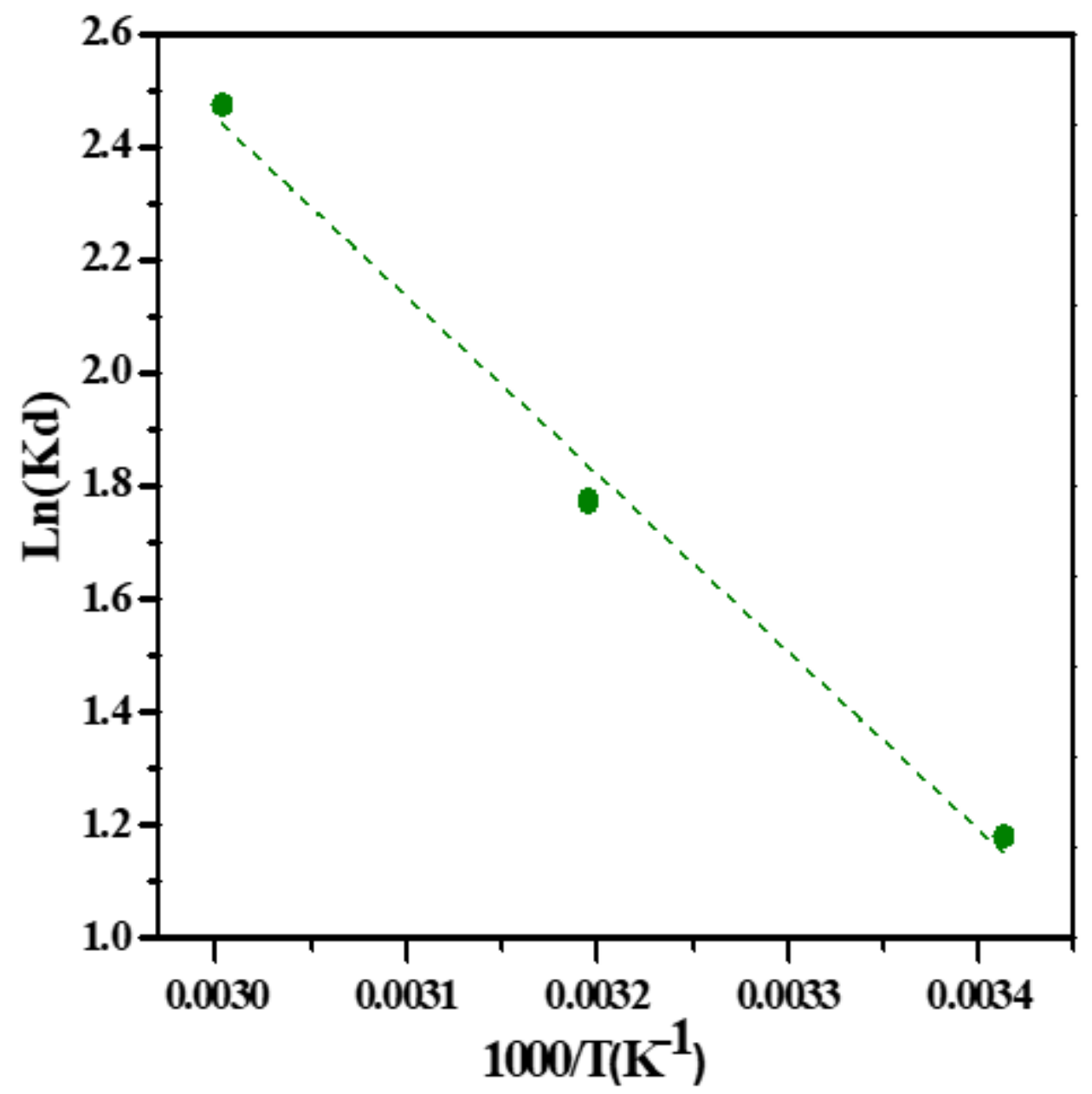

Figure 5

Plot of $\ln (\mathrm{Kd})$ versus 1000/T for As(V) adsorption onto FapC. 

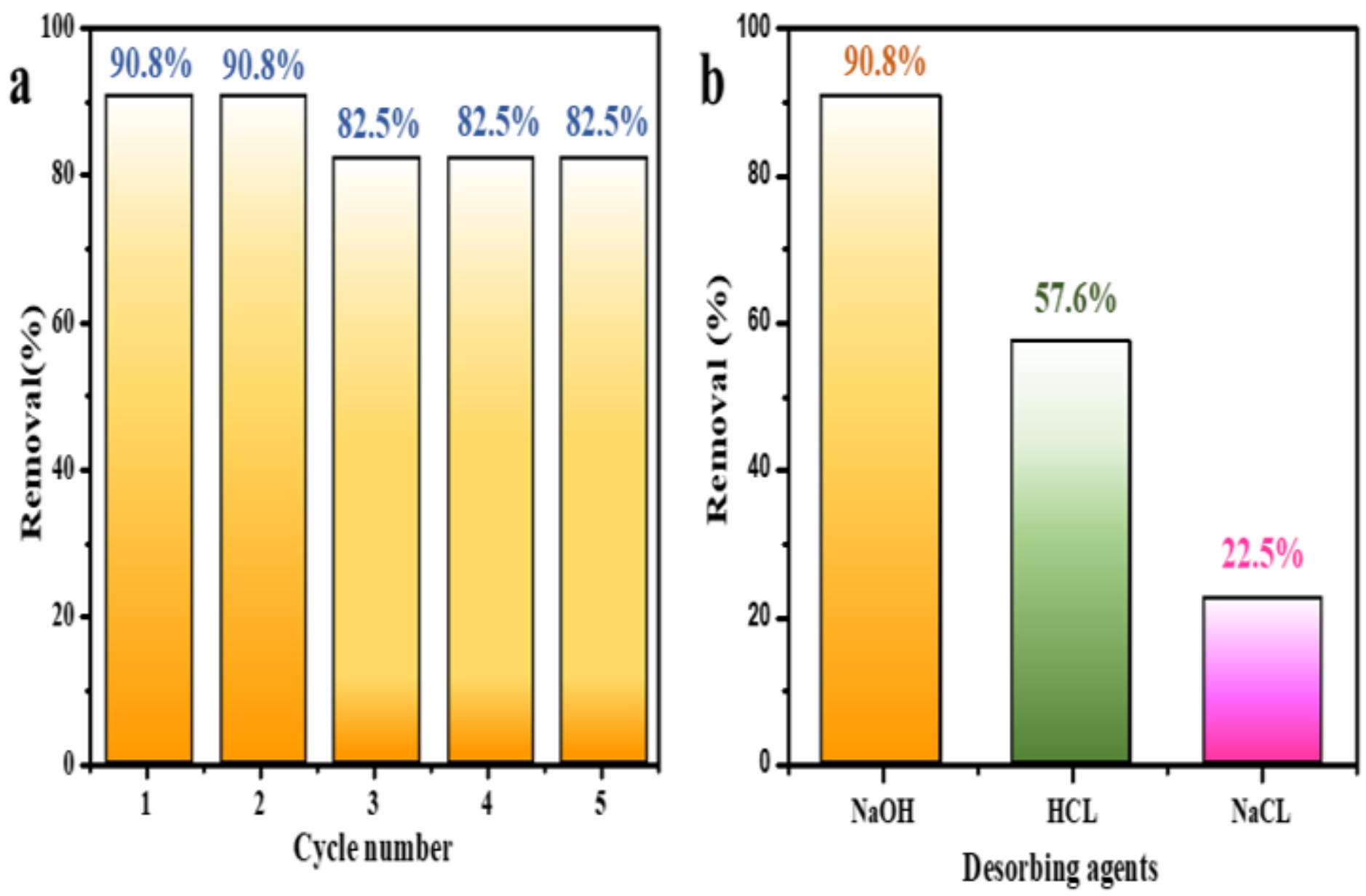

Figure 6

Recycling study of FapC adsorbents 


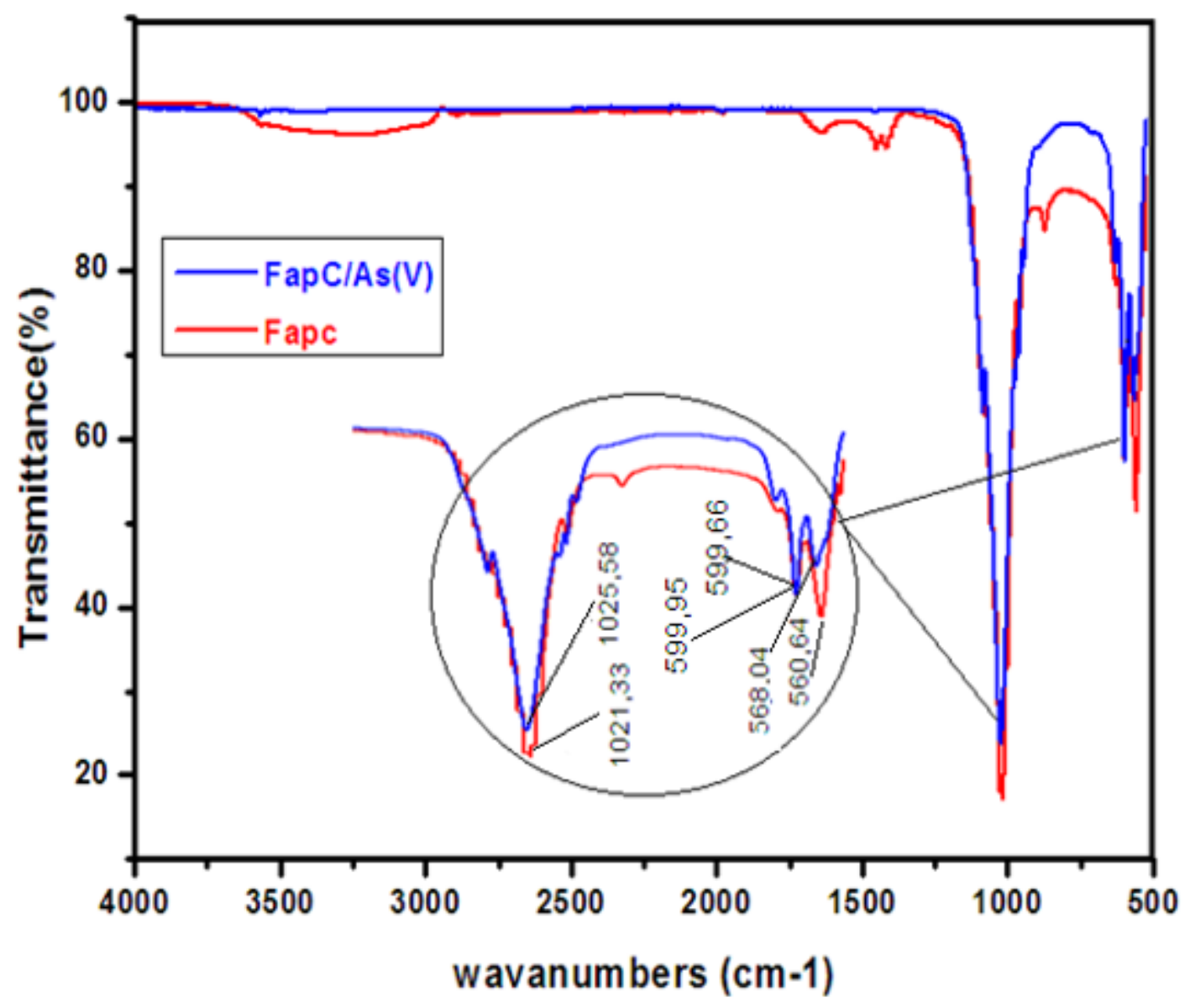

Figure 7

FTIR analysis of FapC after and before sorption of As (V). 